Fecha de recepción: diciembre 2017

Fecha de aceptación: marzo 2018

Versión final: julio 2019

\title{
Los alcances del arte en la elaboración de acontecimientos traumáticos. Una mirada desde los estudios de la memoria
}

Melina Jean Jean *

\begin{abstract}
Resumen: La historia reciente de Argentina estuvo marcada por la represión desplegada durante el terrorismo de Estado en los setenta. Este período ha sido considerado como experiencia extrema y traumática de alto alcance social y colectivo. Esto conduce a pensar en las particularidades de la elaboración de pasados recientes de acontecimientos límite por parte de las sociedades afectadas. En este trabajo se pregunta: ¿De qué formas el arte puede colaborar en la elaboración de eventos traumáticos? A partir de un estudio de caso situado en la ciudad de Ensenada, Provincia de Buenos Aires, se analiza los procedimientos y los alcances de prácticas artísticas que conmemoran y homenajean a desaparecidos y asesinados a través de un trabajo colectivo de memorias, en el que participan activamente familiares y allegados de las víctimas.
\end{abstract}

Palabras clave: Eventos traumáticos - Elaboración - Arte - Memorias - Ensenada.

[Resúmenes en inglés y portugués en las páginas 142-143]

${ }^{*}$ Magister en Historia y Memoria por la Facultad de Humanidades y Ciencias de la Educación (FaHCE). Licenciada y Profesora en Historia del Arte por la Facultad de Bellas Artes (FBA), de la Universidad Nacional de La Plata (UNLP). Becaria de investigación del Instituto de Investigaciones en Humanidades y Ciencias Sociales (IdIHCS, UNLPCONICET). Doctoranda en Historia (FaHCE, UNLP).

\section{Introducción}

La experiencia del terrorismo de Estado de los años '70 en Argentina expresó un proceso que tuvo como resultado profundas transformaciones sociales. Se ejercieron censuras, condenas, torturas, desapariciones, asesinatos, y una larga lista de violaciones a los derechos humanos. Se apuntó a sectores profesionales, intelectuales, educativos, religiosos, artísticos, a movimientos vecinales, grupos culturales, y diversas entidades civiles. Sin embargo, fue la clase trabajadora -en especial los obreros, delegados de fábrica, dirigentes sindicales de base, estudiantiles y barriales-, quienes engrosaron el porcentaje mayoritario de personas desaparecidas y asesinadas ${ }^{1}$. 
La región que conforman las ciudades de La Plata, Berisso y Ensenada, se vio particularmente afectada. El consolidado cordón industrial, la presencia de la Universidad Nacional de La Plata-UNLP-, las luchas obrero/estudiantiles, y la fuerte concentración de fuerza policial y militar contribuyeron a que este territorio de la provincia de Buenos Aires fuese uno de los más golpeados del país (da Silva Catela, 2009). El terrorismo de Estado que basó su metodología sistemática e ilegal en el asesinato y desaparición forzada de personas, tempranamente, movilizó la resistencia de grupos sociales y organizaciones defensoras de los derechos humanos. Desde los últimos años de la dictadura cívico/militar y durante las tres décadas siguientes a la restauración democrática (1983), las principales demandas y acciones giraron en torno a las denuncias y a la condena de las violaciones a los derechos humanos de aquel período; es decir, a la búsqueda de verdad y justicia. A estos reclamos, y en principio en oposición a las políticas de olvido y clausura instaladas desde los propios perpetradores, se sumó la exigencia de memoria. Esto en particular, estableció relaciones con los variados esfuerzos por explicar, comprender y elaborar nuestro pasado reciente. Muchas de estas demandas se tradujeron en prácticas de memoria que a través de diferentes lenguajes -entre ellos los artísticos-, emergieron en el espacio urbano para reclamar y disputar los recuerdos y para conmemorar y homenajear a las víctimas.

Esta investigación propone analizar los procedimientos y los alcances del arte en acciones de y para la(s) memoria(s) mediante un estudio de caso: el proyecto "Mosaicos por la Memoria" que lleva adelante el grupo Espacio de Cultura y Memoria El Rancho Urutaú, en la ciudad de Ensenada desde el año 2010. Se trata de las representaciones plástico/ visuales de desaparecidos y asesinados -en su mayoría obreros-, que se soportan en murales con técnica de mosaico, emplazados en los barrios a los que pertenecían los homenajeados. Estos murales, a escala urbana, privilegian representaciones figurativas, que a partir de una narrativa humanitaria recuperan un perfil identitario que apela a aquello cotidiano, lúdico, y ameno de la vida de esas personas. Hasta el momento son cuatro los murales inaugurados:

- Fortunato "Nato" Andreucci-2,61 x 0,17 x 2,70m-, inaugurado el 05/03/11 (Ver Figura 1). En él se exhibe a un delegado de la sección fundición de la fábrica Astillero Río Santiago, secuestrado y asesinado por la Triple A, el 16 de marzo de 1976. El mural fue emplazado en la plazoleta "Herminio Masantonio" a metros de su hogar.

- Mario Gallego y María del Carmen Toselli-2,92 x 0,14 x 2,44m-, inaugurado el 04/06/11 (Ver Figura 2). Mario fue trabajador de las fábricas Astillero Río Santiago y Propulsora Siderúrgica, militante de montoneros, secuestrado y desaparecido entre 1976 y 1977. María del Carmen era ama de casa y fue secuestrada y violentamente torturada en 1976, siendo insulina dependiente tras ser liberada en graves condiciones de salud, al año falleció. El mural está emplazado al inicio del camino hacia el Club Regatas, a una cuadra de la casa de la pareja homenajeada.

- Carlos Esteban Alaye -2,90 x 0,17 x 2,82m-, inaugurado el 15/04/12 (Ver Figura 3). Estudiante de Psicología en la UNLP, ligado al movimiento obrero y militante de montoneros, fue secuestrado y desaparecido el 5 de mayo de 1977. El mural fue emplazado sobre la calle Mosconi, a una cuadra de la entrada a YPF (Yacimientos Petrolíferos Fiscales) y a pocos metros de la que fuera su casa. 
- Carlos Guillermo Díaz y Marta Susana Alaniz -3,07 x 3, 40m-, inaugurado el 26/04/14 (Ver Figura 4). Carlos era estudiante de Educación Física de la UNLP y trabajador de Servicios Eléctricos del Gran Buenos Aires -SEGBA-. Marta era psicóloga egresada de la UNLP y trabajadora de Vialidad. Ambos militaban en el Ejército Revolucionario del Pueblo -ERP-. Fueron secuestrados y desaparecidos el 10 de marzo de 1977. El mural fue emplazado en una pared frontal de la Escuela Primaria No 9 de Villa Tranquila, a la cual había ido Carlos.

A través del proyecto, el Rancho Urutaú pretende "emerger del silencio en que se ha sumido a la ciudadanía (...), esclareciendo la historia inmediata, para sintetizar la experiencia y que el "Nunca Más” sea un hecho" (Rancho Urutaú, 2011)². Además, busca reconstruir el entramado social que directa o indirectamente fue intervenido durante la última dictadura en la Ciudad, restableciendo vínculos, regenerando lazos con los familiares, allegados y vecinos de los homenajeados. Lo que interesa indagar es la recepción de los murales en los familiares y allegados de los homenajeados, y entre los propios integrantes del grupo hacedor, focalizando en la dimensión afectiva -vivencias, sensaciones, recuerdos, interrogantes-, que produce cada experiencia. Es decir, indagar en las subjetividades actuales que devienen del hecho histórico -las desapariciones y asesinatos en la ciudad- y el (re)encuentro con cada mural. Para ello, resulta fundamental analizar el tipo de representación seleccionado por el grupo, la técnica, la modalidad de trabajo, los procesos de construcción de los murales y el grado de participación de los familiares y allegados. Esto conduce a un trabajo interdisciplinar que cruza los campos de la Historia, la Memoria y los estudios del Arte. Desde una metodología de corte cualitativo y a través de la aproximación analítica de un estudio de caso, en este artículo presentamos los resultados obtenidos -a partir de observaciones participantes y entrevistas abiertas y semiestructuradas-, de la indagación que aborda particularmente el binomio arte-memoria. 


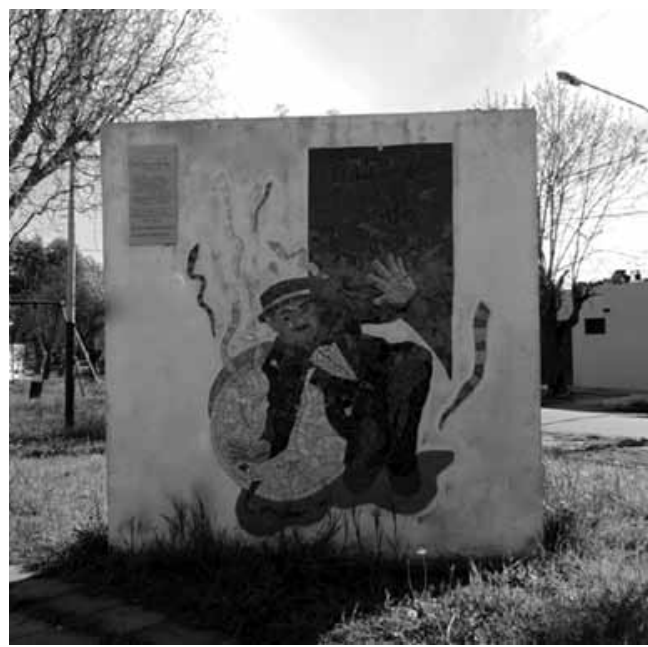

Figura 1.

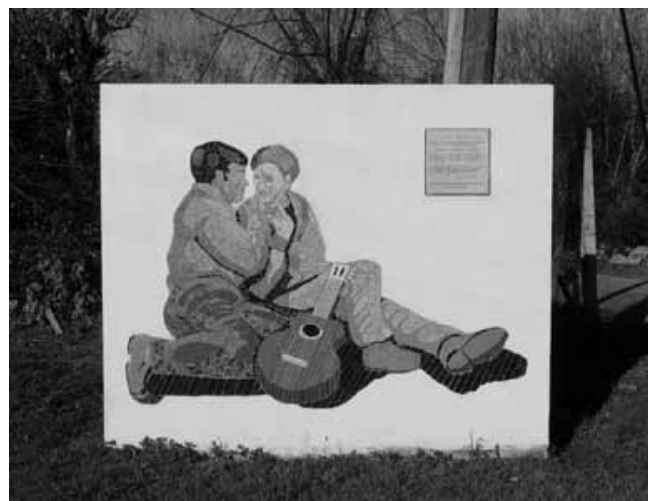

Figura 2.

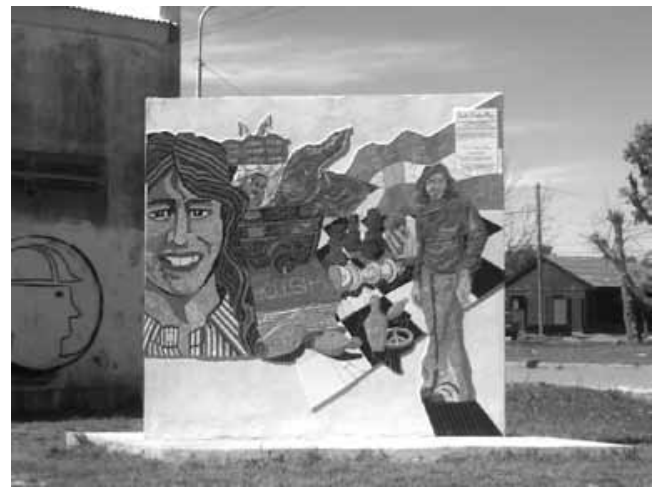

Figura 3.

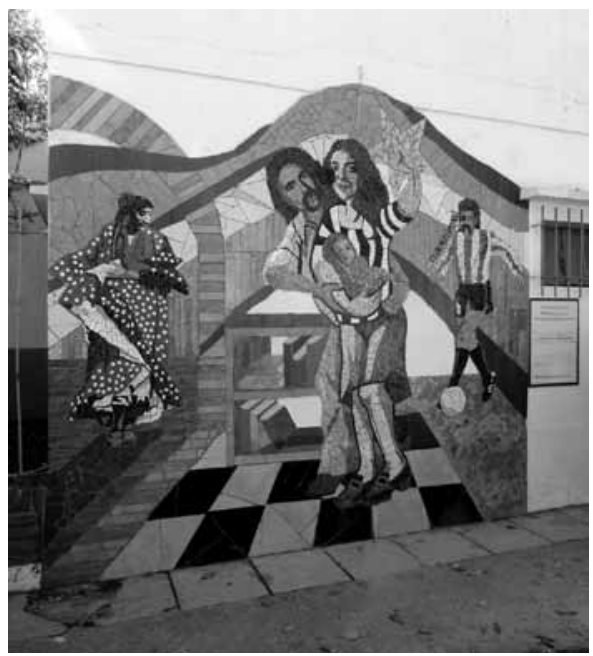

Figura 4.

Figura 1: Mural "Fortunato "Nato" Andreucci". Fuente: elaborada por Melina Jean Jean. Figura 2: Mural “Mario Gallego y María del Carmen Toselli”. Fuente: elaborada por Melina Jean Jean.

Figura 3: Mural "Carlos Esteban Alaye”. Fuente: elaborada por Melina Jean Jean.

Figura 4: Mural "Carlos Guillermo Díaz y Marta Susana Alaniz”. Fuente: elaborada por Melina Jean Jean. 


\section{El arte y el trabajo colectivo de construir memorias}

En primer lugar, se parte de considerar a la memoria como categoría social (Jelin, 2002) y a la memoria colectiva (Halbwachs, 2011) como aquella a la que hacen alusión política los actores sociales. En este sentido, se retoma el concepto de "marcos sociales de la memoria" (Halbwachs, 2004, p. 8-10) para poder plantear la posibilidad de reconstrucción creativa de una memoria colectiva y, en esta investigación, de su representación como proceso social. Los marcos sociales son aquellos instrumentos que permiten fijar los recuerdos para darles un sentido articulándolos con elementos y puntos de referencia que, construidos en instituciones como la familia, los grupos religiosos o las clases, entre otros, permiten precisamente servir de estructura de asimilación a las experiencias personales. La memoria colectiva en tanto proceso social de reconstrucción creativa emerge como producto de interacciones múltiples de las memorias compartidas, en marcos de referencia y en situación de disputas por el poder. Ahora bien, ¿qué sucede con la memoria de hechos traumáticos acontecidos en el pasado reciente de una sociedad? La memoria, el recuerdo, la conmemoración o el olvido, se tornan cruciales cuando se vinculan a experiencias trágicas y traumáticas colectivas de represión y aniquilación. En estos casos, la memoria y el olvido cobran una significación especial como mecanismo cultural para fortalecer el sentido de pertenencia en sociedades que han sufrido períodos de violencia y trauma. La investigadora Jelin (2005) afirma que "las exclusiones, los silencios y las inclusiones a las que se refieren hacen a la re-construcción de comunidades que fueron fuertemente fracturadas y fragmentadas en las dictaduras y los terrorismos de estado" (p. 223). Las luchas por la memoria, por los sentidos de ese pasado reciente en el presente se convierten en luchas políticas. Dentro de este proceso, los diferentes actores despliegan estrategias de hacer memorias diversas. Estos "emprendedores de memoria" (Jelin, 2002, p. 48), asumen el rol activo de promover la transmisión de esa memoria a la sociedad presente y a las generaciones futuras. Sujetos que en muchos casos no tienen relación directa con las víctimas, los sobrevivientes o los familiares, pero que sin embargo, reviven el sentido de pertenencia a ese pasado desde el presente, considerándose parte de esa memoria no ya individual sino colectiva, razón que los lleva directamente a la acción y a la necesidad de transmitirla y materializarla. Estas observaciones, permiten comprender la conformación y el funcionamiento del grupo Rancho Urutaú y su proyecto Mosaicos por la Memoria inaugurado como tal el 27 de marzo del año 2010. Se trata de alrededor de diez a quince ciudadanos ensenadenses, que en su mayoría tenían algún tipo de relación previa. No siempre fueron los mismos, a veces rotaron en su participación, algunos se alejaron y continuamente se sumaron y suman integrantes nuevos. De un rango etario de 35 a 75 años, los integrantes son de origen social distinto, ideologías diferentes, oficios, trabajos, profesiones y ocupaciones diversas, entre los que se encuentran participando familiares y allegados de desaparecidos y asesinados. Esta diversidad de identidades individuales que conforman al grupo, quedan atravesadas por un pasado que los identifica colectivamente. Los integrantes del proyecto se unen a partir de compartir experiencias en igual sentido respecto a las consecuencias del terrorismo de Estado en la ciudad a la que pertenecen. Es esta memoria colectiva la que se activa en el proyecto. Como lo afirman en su única publicación gráfica hasta el momento: "hacer memoria de lo reciente y revisar aquel 
momento de crisis en donde todo tipo de instituciones en nuestra vida social, pública, se desintegraba" (Rancho Urutaú, 2011, p. 2) 3 $^{3}$ En cuanto al funcionamiento, si bien algunos ofician de coordinadores, el trabajo es horizontal y colaborativo. Las decisiones se toman en conjunto mediante reuniones, debates y votaciones. El proyecto se divide en tres etapas que denominamos: proceso de investigación; proceso plástico y emplazamiento; difusión, inauguración y acto conmemorativo. Las actividades se reparten de manera a veces azarosa y también en función de las posibilidades, intenciones, accesibilidad y habilidad -en cuanto al manejo de los lenguajes artísticos- de los integrantes. Durante el proceso de investigación, se intenta recopilar toda la información disponible del homenajeado y la fuente principal son las familias y allegados. De este procedimiento surgen las primeras imágenes y los bocetos de la futura composición, que serán trabajados durante el proceso plástico. Una vez realizado el boceto final, se traslada la composición a un papelón aproximadamente del tamaño de la pared soporte del mural. Las figuras son trabajadas con la técnica de mosaico indirecta, los fondos con la técnica directa sobre la pared ya levantada y preparada para el emplazamiento. La elección de esta técnica está fundamentada por su perdurabilidad en el tiempo, y por el tipo de emplazamiento en el espacio urbano que el grupo decidió emplear. La consigna es colocar el mural lo más cercano posible a la casa del homenajeado. Esta decisión responde a una búsqueda estratégica en relación a sus objetivos que radican en que el mural sea visibilizado por los familiares y vecinos del barrio. Los murales entonces adquieren particularidades tales como la monumentalidad, poliangularidad, una estructura interna de composición, una determinada relación con el entorno social y físico, y la importancia del observador, ya sea dirigido o transeúnte ocasional. Demandan y permiten el trabajo en equipo, se insertan en alguna problemática específica del barrio o la comunidad en la que se encuentran (Di María, et. al, 2009). La técnica de mosaico posibilita la participación de todos, y su puesta en la escena pública anhela la circulación y apropiación de éstos por parte de la comunidad barrial. La Municipalidad de Ensenada se encarga - por pedido del Rancho Urutaú-, del levantamiento de la pared. También colaboran con el sonido y escenarios para la inauguración y el acto conmemorativo. En esta última etapa, el grupo se divide en comisiones, una de organización del acto, la otra de difusión y prensa. La difusión se hace a través de medios gráficos, radiales y/o televisivos ensenadenses, en redes sociales de Internet, y en el espacio urbano de la ciudad a través de volantes, afiches, folletos, pasacalles, etc. El sustento económico para el funcionamiento del proyecto proviene del aporte de los propios integrantes, sumado a la realización de rifas, y a donaciones que consiguen de $-\mathrm{u}$ ofrecen-, familiares, allegados, vecinos, algunos gremios, instituciones, y en algunas ocasiones de la Municipalidad.

\section{El arte y las representaciones del horror}

La historia reciente de nuestro país estuvo marcada por la experiencia límite que significó la represión desplegada por el terrorismo de Estado en los años'70. Este período ha sido considerado como experiencia extrema y traumática de alto alcance social y colectivo. Esto conduce a pensar en las particularidades de la elaboración de pasados recientes de acontecimientos límite por parte de las sociedades afectadas. Desde la perspectiva de la 
adecuación de las representaciones posibles, este tema ha sido tratado y discutido por historiadores, filósofos, antropólogos, artistas, políticos, teólogos, entre otros. El tropo fundamental en torno al que han discurrido las cuestiones de representación y narración ha sido el Holocausto, estimado como situación límite que exige un esfuerzo desconocido para poder ser atrapado en las narrativas conocidas, sin definir si realmente puede ser contado, explicado, o si puede llegar a ser cumplida la exigencia generacional y política de su emergencia completa, y de su transferencia a las generaciones futuras. Esta interpretación del Holocausto tuvo lugar a principio de los años '80. En esa coyuntura y siguiendo a Huyssen (2002), en contraste con la mirada hacia el futuro -característica de la modernidad occidental de la primera mitad del siglo XX-, se activó en Europa y en los Estados Unidos una pulsión memorialista: el surgimiento de la memoria como fenómeno cultural y político. Distintos eventos acompañaron este fenómeno como el debate de los historiadores alemanes sobre el Holocausto (Historikerstreit); los cuadragésimos y quincuagésimos aniversarios -de simbólica carga política y masiva cobertura mediática- del ascenso de Hitler al poder (1933), recuperado en 1983; la invasión de Normandía en 1994; y el fin de la Segunda Guerra Mundial, evocado en 1995, entre otros. También por la erección de monumentos recordatorios, museos y producciones cinematográficas y para televisión, que extendieron el tema y avivaron su interés global. Sin embargo, estas reflexiones y discusiones no hicieron más que evidenciar la existencia concreta de intentos por narrar, describir y representar acontecimientos de experiencias traumáticas. En efecto, esta situación límite que se plantea para la narrativa histórica y exige reflexión y cuidados tanto epistemológicos como morales, también se desplazó hacia el terreno de los lenguajes estéticos y las representaciones artísticas de este tipo de hechos. El arte ha mantenido un lugar muy cercano y privilegiado como mediador en la elaboración de experiencias traumáticas, en tanto sus lenguajes y la especificidad de sus materialidades y procedimientos pueden eludir la exigencia de racionalidad de los textos epistémicos, redimensionar la transferencia de mensajes, y hasta impulsar el acercamiento al pasado traumático. Cuando lo que está en juego es lo que rompe el sentido y la posibilidad de contarlo, el trabajo del arte es eficaz y es capaz de insinuar vías de reflexión a las que, por causas de rigorismo, no siempre pueden sumarse las disciplinas tradicionales (Gatti, 2011, p. 150).

De acuerdo a Battiti (2005), en Argentina resulta asombrosa la cantidad y calidad de las elaboraciones estéticas que se asoman a la representación de acontecimientos límites y se constituyen en configuraciones de la memoria social. Para la autora, "el arte proporciona modos de reflexión cualitativamente distintos a los testimonios, la documentación o los relatos orales; registros que pueden coexistir y retroalimentarse en la construcción de discursos públicos sobre la memoria” (p. 103). Por su parte, García y Belén (2010) manifiestan que el arte ha sabido responder a las preguntas por la representación de lo irrepresentable, lo indecible, lo invisible y los silencios. Estas prácticas estéticas pueden alcanzar lo que no lograron las palabras, captar las huellas del horror, volver visibles las huellas de lo invisible. Acaso la particularidad de la última dictadura y sus desaparecidos ha sido fuente inabarcable hasta la actualidad para la evocación de su recuerdo a través del arte. De esta forma, el lenguaje artístico se erige propiciamente para interrogar y construir relatos desde las ausencias. 


\section{Representar las desapariciones: la estrategia artística del Rancho Urutaú}

En Argentina, la lucha del movimiento de derechos humanos estuvo enfocada desde sus inicios en las denuncias, intentando quebrar el silencio en torno a las desapariciones. En ese afán y en esa urgencia, el objetivo fue hacer visibles a los desaparecidos. Según Feld (2010), el rol que las imágenes tuvieron en la denuncia y visibilidad de la desaparición fue múltiple y varió con el tiempo. Las imágenes se vincularon con distintos contextos institucionales y estuvieron a cargo de actores diversos. Sin embargo, se puede identificar, desde este movimiento, la producción de una "iconografía particular" (Feld, 2010, p. 56), o como lo han denominado otros autores: "estrategias visuales" (Longoni y Bruzzone 2008), "políticas creativas, políticas visuales o performáticas" (Longoni, 2010), "conjunto de prácticas, símbolos e íconos" (Schindel, 2009).

Siguiendo a da Silva Catela (2009), las fotografías de DNI o carnet, han sido la manera más directa de tornar visible la desaparición y han funcionado como uno de los soportes centrales para la reconstrucción de la identidad de cada una de las personas secuestradas, asesinadas y desaparecidas. En un principio, las fotografías fueron utilizadas por los familiares en sus recorridos por comisarías, hospitales, dependencias gubernamentales y eclesiásticas. Luego se transformaron en carteles o pancartas que sostuvieron a lo alto en las primeras rondas de Plaza de Mayo, y también en las posteriores marchas. La imagen se acompañaba con el nombre y la fecha del secuestro, y a veces algún dato sobre su profesión u ocupación. En cuanto a las siluetas, para Longoni (2010) éstas conforman la otra gran matriz de representación del desaparecido junto con las manos y las máscaras. Según Burucúa y Kwiatkowski (2014), las siluetas forman parte de una nueva fórmula de representación que describe, narra y expone los nuevos horrores acontecidos a partir de las grandes matanzas y genocidios del siglo XX, y en el caso argentino particularmente del horror de las desapariciones. Esta fórmula contiene el recurso de la silueta, la duplicación y la réplica. El ejemplo que eligen estos autores para ilustrarlo es El Siluetazo: la primera práctica masiva de representación de los desaparecidos con siluetas, que tuvo lugar en la tercera Marcha de la Resistencia convocada por las Madres de Plaza de Mayo el 21 de septiembre de 1983, aún en tiempos de dictadura. Como sostienen Longoni y Bruzzone (2008), el impacto simbólico producido por los primeros Siluetazos produjo la reiteración de las siluetas como forma de representación de los desaparecidos. El modo de representación seleccionado por el Rancho Urutaú presenta ciertas particularidades. En todas las composiciones, construidas a través de mosaicos, cobra especial relevancia la figuración como recurso. Lo que unifica y caracteriza a todas estas obras es el uso de figuras humanas que tienen identidad, un rostro, cuerpo, gestos, poses, y una serie de elementos que acompañan a las figuras y condensan simbólicamente sus gustos, costumbres y actividades cotidianas. En estas representaciones, la militancia, el compromiso político, lo revolucionario o el heroísmo, en la imagen global del mural cuando no está ausente, apenas aparece. Por otro lado, la condición de desaparecido o asesinado de esas personas no puede conocerse a través de la imagen. Es en las placas de cerámica colocadas a un costado de los mosaicos donde hallamos esta información a través de la palabra. Allí se refuerza el tipo de representación mediante términos que aluden a lo familiar. Se menciona la ocupación y aquellos valores en los que el homenajeado creía y, en algunos casos, se alude a la mili- 
tancia. Para este tipo de composición, ya mencionamos que el grupo indaga en el entorno familiar y de allegados, en búsqueda de toda información posible del homenajeado. En estas imágenes plástico/visuales, la reconstrucción del rostro y el cuerpo alcanza un estatuto decisivo para darle identidad a las figuras. A tal efecto, el grupo parte de la utilización de otras imágenes: las fotografías que las familias comparten con ellos durante la etapa de investigación. Se trata, en su mayoría de fotografías íntimas, familiares y fotos de DNI y carnet. No obstante, pese a las dificultades devenidas ante la insuficiencia o baja resolución de las mismas, el equipo exploró su lado más creativo buscando otros recursos para su composición -por ejemplo sumando como referencias imágenes de Internet de murgueros bailando para el caso de "Nato" Andreucci y de jugadores de fútbol de la época, para el caso de Carlos Díaz-. En este sentido, consideramos que las imágenes plásticas conllevan -y aún más, refuerzan-, aquello que revelan las fotografías familiares y de carnet: la vida previa a la desaparición o el asesinato. Mientras las siluetas remarcan la cuantificación de las víctimas, la dimensión del vacío y su ausencia masiva, es decir, representan la magnitud del terrorismo de Estado (Longoni, 2010; Burucúa y Kwiatkowski, 2014), las fotografías remiten a identidades particulares, a sujetos concretos. Que además, "muestran personas felices o despreocupadas, en medio de acontecimientos que convencionalmente se consideran hitos de la historia de cada familia" (Longoni, 2010, s/p).

Se puede plantear que esta elección figurativa e identitaria -que privilegia una dimensión humana, cotidiana, amena y lúdica de la persona-, se justifica en tanto que su recepción genera un recuerdo distendido y hasta placentero del personaje. Esto puede llevar a pensar en la construcción de una narración ideada para desplazar las huellas del trauma. El dispositivo de desaparición generó experiencias traumáticas extendidas ampliamente entre la población,

Creando un hueco en la capacidad de «ser hablado» o contado. Se provoca un agujero en la capacidad de representación psíquica. Faltan las palabras, faltan los recuerdos. La memoria queda desarticulada y sólo aparecen huellas dolorosas, patologías y silencios. Lo traumático altera la temporalidad de otros procesos psíquicos y la memoria no los puede tomar, no puede recuperar, transmitir o comunicar lo vivido (Jelin, 2002, p. 36).

Además, como sostiene Feierstein (2012) referenciando a Kaës (1991), el trauma se produce y se renueva en tanto experiencia histórico/social. El sujeto ni vive ni experimenta solo ninguna situación traumática, sino que "tanto la vivencia como la sensación que ésta produce, se dan en el contexto de la relación significativa con otros. La vergüenza, el dolor, el terror se sienten en función de otro" (p. 76). No obstante, podemos agregar que la experiencia siempre es subjetiva. Asimismo, la experiencia traumática, según LaCapra (2006) tiene un aspecto evasivo porque se relaciona con un pasado que no ha muerto: un pasado que invade el presente y puede bloquear o anular las posibilidades en el futuro. La denominada memoria traumática traslada la experiencia del pasado -no superado, y como si no hubiera distancia- al presente y al futuro, al revivir o re-experimentar compulsivamente los acontecimientos. En la memoria traumática, el pasado continúa vivo en la experiencia, 
$\mathrm{Y}$ atormenta o posee al yo o a la comunidad (en el caso de acontecimientos traumáticos compartidos). Es necesario elaborarlo para poder recordarlo con cierto grado de perspectiva crítica y control consciente que permita la supervivencia (...). Elaborar la experiencia de estos acontecimientos de maneras viables y ética y políticamente deseables- es uno de los mayores desafíos que presentan los traumas personales o colectivos a los sobrevivientes, a sus allegados $\mathrm{y}$, en ciertos aspectos, a todos los que conviven con una herencia cargada o responden empáticamente a un pasado todavía vivo, y a los que aún viven en él (LaCapra, 2006, p. 83).

Como una posible respuesta al trauma, entonces, la elaboración,

Es un quehacer articulatorio: en la medida en que elaboramos el trauma (así como las relaciones transferenciales en general), nos es posible distinguir entre pasado y presente, y recordar que algo nos ocurrió (o lo ocurrió a nuestra gente) en aquel entonces, dándonos cuenta empero de que vivimos aquí y ahora, y hay puertas hacia el futuro (LaCapra, 2005, p. 46).

La elección figurativa en tono ameno que construye el grupo junto a los familiares y allegados -pues estos son siempre consultados y se espera su aprobación de la composición-, también puede pensarse y conceptualizarse como un fetichismo narrativo (Santner, $2007)^{4}$. Este funciona como una respuesta frente al pasado traumático e intenta sustituir el trabajo de duelo o elaboración del trauma que necesita del gasto de angustia para ser efectuado. Es decir, "tanto el fetichismo narrativo como el duelo son respuestas a una pérdida, a un pasado que se resiste a marcharse por obra de su impacto traumático" (Santner, 2007, p. 221). Desde el punto de vista psicoanalítico freudiano, el fetiche es aquel objeto que reemplaza el lugar del deseo y del placer. Siguiendo la explicación de Santner (2007), durante el trabajo de duelo se elabora la realidad de la pérdida (o el shock traumático) recordándola y repitiéndola en diferentes dosis y formas, lo cual, en un contexto terapéutico implica la dosificación de gasto de angustia. El principio de placer $^{5}$ se encuentra en ese momento fuera de acción. Pero el fetichismo es la oposición y negativa a este proceso porque permite precisamente rehabilitar el principio del placer. Como estrategia desarticula a través del placer y la fantasía la necesidad de hacer el duelo, evitando caer en la urgencia de la reparación del suceso traumático. Podemos pensar que el tipo de representación elegido en los murales alivia en sus hacedores y observadores el peso de tener que reconstruir la propia identidad colectiva en condiciones postraumáticas; es decir, propone la postergación indefinida del trauma y la cancelación de su elaboración con la consiguiente evitación de gasto de angustia. Por su parte, el Rancho Urutaú plantea en sus obras la existencia de ausencias a través de la imagen en vida de esas ausencias como forma de representarlas. Se exhibe lo que se perdió: la vida compartida de esos vecinos y se hace a partir de la figuración humana, la identidad, y de un momento placentero en la vida de esa persona siendo no doloroso de recordar. Esta operatoria, que podríamos reconocer como un caso de fetichismo narrativo, conduce a un desplazamiento del núcleo doloroso de la memoria traumática. Esta es clave para los objetivos de memoria del grupo. La evidencia la aportan 
los mismos integrantes cuando explican los motivos de su elección. También los familiares y allegados cuando narran su experiencia de encuentro con el mural. Sin embargo, a pesar de relatar el gusto, el placer y la alegría con la que aceptaron la imagen y participaron de la construcción del mural, en todas las entrevistas, lo primero que afloraron fueron las biografías y recuerdos de los últimos momentos antes del secuestro de su ser querido, y luego los relatos sobre el horror ante la desaparición, la desesperación, incertidumbre y el dolor. Entonces, también se puede agregar que a la experiencia traumática de la violencia sufrida, se suma la imposibilidad de un duelo a llevar a cabo por parte de los familiares y allegados de los desaparecidos, ya que, en la medida en que la ausencia derivada de la desaparición implica la ausencia del cuerpo y por lo tanto la ausencia de los ritos culturales que se inscriben en torno a la muerte, el duelo queda de ese modo suspendido, latente. Como afirma da Silva Catela (2009),

En los procesos "normarles" de muerte, donde existe un cuerpo para dar sepultura, el cementerio es el espacio que divide el mundo de los vivos del mundo de los "muertos", es un espacio fundado en lógicas propias donde las marcas del parentesco, de filiación, de clase social, de pertenencia a grupos aparecen por todos lados como señales de quién es la persona que está allí sepultada. De cierta forma la marca de la sepultura funciona como un operador que "integra en una estructura meta-histórica al grupo social desgarrado por la muerte" (Faeta, 1993) recrea en un nuevo espacio las relaciones de parentesco, sociales y culturales rotas por la muerte. Con la falta del cuerpo, locus esencial de los rituales de la muerte, ¿qué espacios son recreados para dar cuenta de esa ruptura? (p. 114).

Siguiendo a la autora, se puede pensar que los murales -en tanto soportes de memoria-, funcionan como salidas creativas y necesarias en los familiares y allegados para dar cuenta de estas ausencias. Las imágenes de su ser querido materializadas en las paredes colocan a disposición nuevos objetos que encierran lo que ha desaparecido, tornándolos disponibles a manera de ritual de recuerdo. Si bien esto por sí solo no resuelve la elaboración del trauma, se adecúa a los rituales culturales de la muerte que son habituales en las personas. Puede cancelar la incertidumbre, cerrar la incógnita y aliviar la insistencia del dolor psíquico. A su vez, los murales reinstalan en el paisaje del barrio a los desaparecidos, quienes fueron sistemáticamente negados por los mandos militares en el pasado, y aún en el presente, cuando continúa vigente entre ellos el pacto de silencio sobre su destino. Al crimen clandestino, al cuerpo desaparecido, le continuó el ocultamiento de toda prueba y documentación de la existencia de la persona: desaparecer el cuerpo, desaparecer su identidad. Frente a esto, en los murales reaparecen los cuerpos y junto a todos aquellos elementos identitarios reunidos en cada imagen, se transforman en fragmentos de vida, en un acto político, socavando el doble vacío dejado por las desapariciones. 


\section{Consideraciones finales}

A partir de entrevistas realizadas ${ }^{6}$, se ha podido plantear que la recepción de las imágenes en los murales fue aceptada y bien acogida. Tanto en los integrantes del grupo como en los familiares y allegados se advierte que la interpretación y el acontecimiento de posar la mirada en la figura reivindicada, en su identidad rehumanizada, es curativo o reparador en alguna medida. Por otro lado, la narrativa humanitaria y familiar utilizada para representar a los desaparecidos y asesinados, según Crenzel (2008), fue adoptada a partir de un cambio en la clave de las denuncias -basadas en la cultura política de los derechos humanos-, durante los últimos años de la dictadura y posteriormente tornada dominante a partir del informe titulado: Nunca Más realizado por la CONADEP (1984). Esta restitución de la humanidad y despolitización, en tanto víctimas inocentes se correspondió, entre otras cosas, a la confrontación con la postura dictatorial de negar la existencia misma de desaparecidos, o al hecho de que caracterizaran a estas personas -en un discurso estigmatizante y culpabilizador-, como "delincuentes subversivos" (Crenzel, 2008, pp. 46-47), y como una amenaza para los valores familiares, nacionales y cristianos que el gobierno militar decía defender" (Crenzel, 2008, pp. 46-47). También esta clave, de acuerdo al autor formaba parte intrínseca del universo de interpretación de la mayoría de los familiares, para quienes su lazo con el desaparecido se basaba en esos valores, que ignoraban sus adscripciones políticas o que ejercieron un silencio estratégico sobre ellas dada la persecución dictatorial? ${ }^{7}$.

En el caso del Rancho Urutaú, la narrativa humanitaria se presenta como una estrategia de memoria y son la resultante de un proyecto cuyos fundamentos y objetivos fueron detenidamente pensados, debatidos y consensuados colectivamente, junto a la participación de familiares. Esta humanización se refuerza presentando momentos placenteros de las vidas de esas personas porque el fin es precisamente reivindicarlas como tales, destacando sus valores y cualidades -en las placas-. La expectativa básica es de presentar y mantener vivos a los desaparecidos y asesinados a través de la trasmisión y reedición de sus vidas. Estas representaciones pueden funcionar como fetichismo narrativo, en tanto se desplaza aquello que resulta doloroso y traumático de recordar por "algo" -aquí una imagen plástica- que genera placer, postergando de esta forma, el costoso trabajo de duelo. En este sentido, los entrevistados evidencian una recepción emotiva y ambigua que responde a un efecto dual: por un lado, el sentimiento de reconocimiento y de humanización del desaparecido y el placer en el recuerdo de la vida compartida previa a los hechos, con esas personas; y por otro, el registro de la situación traumática en tanto que los murales no dejan de evocar aquellos recuerdos dolorosos de la desaparición o asesinato, y es por esto que se puede pensar al mural como espacio que colabora en la elaboración del duelo y gradual dilución de la experiencia traumática, ayudando a "curarse" de la tragedia. La propuesta del Rancho Urutaú es rehabilitar las ausencias mediante una materialidad que simboliza la vida truncada. Los cuerpos de los ausentes ahora se intercalan con los de los vecinos y transeúntes. Esta materialidad enfrenta la ausencia y ayuda a aliviar el desasosiego y el dolor de los familiares quienes son, o deberían haber sido, los destinatarios legítimos de los cuerpos. De modo consciente el grupo asume la decisión de esta modalidad de representación porque es la que les parece más adecuada para poner en acto su pensamiento: su acuciada 
necesidad de hacer emerger el tema, el reconocimiento, la búsqueda y la reparación de ese pasado traumático de la ciudad "del que no se habla”. Esta es la elección del grupo para enfrentar la conflictividad del tema en Ensenada. Y lo hacen a través del arte como lenguaje, "el arte tiene esa función bastante liberadora de conflictos profundos, y de poder permitir hablar de cosas que son terribles, de lo peor sacar arte", afirma Melina Slobodián (2018), artista y coordinadora general del proyecto ${ }^{8}$.

Aquí el arte funciona como un vehículo de memorias que permiten articular el pasado traumático con el presente desde dispositivos lúdicos y reflexivos. En esto vemos la posibilidad de que una manifestación artística,

Pueda ser leída como una perspectiva significativa y crítica de la relación de una comunidad con su pasado en términos de la memoria del trauma colectivo e individual, con la posibilidad de que el arte, en sus específicas (a menudo muy mediadas, indirectas, oscuramente lúdicas, potentes pero no acotadamente documentales o informativas) formas de testimoniar o ser testigo de ese pasado, contribuya a elaborar y superar ese pasado, y en consecuencia permita acceder a otras posibilidades en el presente y el futuro (LaCapra, 2006, p. 67).

La técnica de mosaico que posibilita la participación colectiva, además, colabora en la reparación psíquica, y en la reconstitución de la identidad anhelada, de aquella vida compartida con los familiares, allegados y vecinos que fuera arrebatada por la dictadura. El acuerdo sobre estas apreciaciones del arte que al interior del grupo se sostiene, es uno de los aspectos de investidura de identidad más pregnante del Rancho Urutaú en el escenario de la Ciudad. Por último, en función de la pretensión de incidir sobre el silenciamiento del tema y en la transmisión a las futuras generaciones, la pregunta que se hacen en el grupo es si lo que nosotros hacemos va a generar lo que nosotros queremos, que es crear conciencia en la gente, que se interioricen, que sepan quienes fueron los desaparecidos, que puede pasar en cualquier barrio ${ }^{9}$. El interrogante acerca de si la operación de intervención en el espacio público con los murales puede sostenerse en el tiempo y convocar o no a los vecinos abre distintas posibilidades a la reflexión. Una de ellas es la de que los murales se naturalicen como parte del mobiliario urbano olvidando su génesis. Esto puede verse reforzado a partir del tipo de representación seleccionado, en tanto que una de las intenciones más importante del Rancho es la de generar empatía para con los vecinos frente a un alarmante y expectante posible rechazo o negación del mural emplazado en su barrio -en sintonía con el propio rechazo o negación del acontecimiento rememorado-: el asesinato y/o la desaparición. Los datos biográficos y característicos de haber sido desaparecido o asesinado están presentes en el mural con una placa alusiva. La superficie visual se concentra en mostrar otros aspectos de la biografía de los personajes y la placa aparece como acotación o anclaje no visible globalmente en la imagen. Esta modalidad se podría fundamentar en la historia de silenciamiento que la ciudad ha construido en torno a la problemática de los desaparecidos, pero puede acontecer que la imagen de cotidianeidad que genera empatía y propicia identificaciones positivas con los ensenadenses, quede por eso mismo relacionada solo con los aspectos lúdicos del personaje y no con el horror de la desaparición y la falta de justicia, resultando lo contrario a lo que el grupo 
hacedor pretende. Un elemento más que aflora a partir de las entrevistas es la constatación de la calidad de lugar sacro del mural. Si bien ningún testimonio conecta su aprecio con alguna fecha conmemorativa en especial, sí se preocupan y ocupan de verificar que la obra se halle siempre en buenas condiciones, que se preserve y mantenga; manifestando una valoración y dedicación particulares. La inexistencia de una sepultura y por ende, de una tumba donde llevar a cabo el duelo y elaboración de la falta, puede conducir a los familiares y allegados a apropiarse simbólicamente del mural donde está representado su ser querido. En este sentido, expresiones registradas en las entrevistas como: "es un cierre", "la culminación de un montón de cosas", "lo tomo como que no hubo tumba", "está entre nosotros", "está presente en cada uno que pasa y lee", "estás acá, no te fuiste" dan cuenta de ello. Lo mismo se observa cuando en la circulación cotidiana por las calles de la Ciudad se produce el encuentro con el mural, y ante la presencia de esa ausencia, el familiar o allegado lo saluda o dirige unas palabras.

Para finalizar, la desaparición es la no muerte. Despojados de toda posibilidad de cancelación cíclica de la vida, sin oportunidad de reconocer en el cuerpo la huella de la muerte, la condición del desaparecido para los familiares y allegados es un continuo presente. De allí la importancia y la fuerza de este acto de memoria. En su conjunto, se considera que estas apreciaciones definen que para el Rancho Urutaú, los familiares y allegados, el espacio marcado en el barrio, asume la cualidad de lugar de memoria. Un lugar de memoria que a través del arte como lenguaje transmite los intensos y complejos trabajos por conocer, reconocer, elaborar y reparar simbólicamente las heridas, las ausencias y los silencios que caracterizan a este pasado que no pasa en la ciudad de Ensenada.

\section{Notas}

1. Según el informe de la CONADEP, los porcentajes de víctimas de la represión que continúan desaparecidas o que fueron liberadas después de pasar por centros clandestinos de detención son: obreros $30,2 \%$, estudiantes $21 \%$, empleados $17,9 \%$, profesionales $10,7 \%$, docentes 5,7\%, autónomos y varios 5\% (2016, p. 296). Entre obreros, empleados y docentes suman un $54 \%$ y casi un $30 \%$ entre estudiantes y profesionales.

2. En: "Rancho Urutaú, Proyecto "Mosaicos por la Memoria" Desaparecidos de Ensenada" 11 de abril de 2011, Disponible en: https://www.facebook.com/notes/el-rancho-uru tau/proyecto-mosaicos-por-la-memoria-desaparecidos-deensenada/107189206034151/

3. "Nada se pierde,... todo se transforma" artículo que formó parte de la publicación Un recorrido de nueves meses. Resumen de actividades del Espacio Cultural y de la Memoria El Rancho Urutaú. Boletín informativo cuyo título alude a la duración del proceso de construcción del primer mural. Se trata de un resumen de actividades del grupo del año 2011. 4. Erik Santner escribe en el contexto de los debates sobre las representaciones del trauma, la historización del nazismo y la solución final que mencionamos anteriormente. Discute en particular la dinámica del fetichismo narrativo en el cine "ámbito de producción cultural donde el placer narrativo y el placer visual se entremezclan libremente". Toma como ejemplo el filme alemán Heimat de Edgar Reitz (1984) en el cual a través de un relato de amor se restaura el placer de la narración histórica de la historia alemana del siglo XX. Este 
relato como fetiche desplaza el trauma generado por la solución final y la Alemania nazi, contexto de fondo del filme.

5. Para la teoría psicoanalítica freudiana, el principio del placer es uno de los dos principios, que rige el funcionamiento mental: el conjunto de la actividad psíquica tiene por finalidad evitar el displacer y procurar el placer. El displacer va ligado al aumento de las cantidades de excitación, y el placer a la disminución de las mismas (Laplanche y Pontalis, 1971). 6. Se realizaron un total de 29 entrevistas a: integrantes del grupo, familiares y allegados de los homenajeados (hijos/as, hermanas, esposas, nietos, compañeros de trabajo y militancia, vecinos/as) y funcionarios públicos de la Municipalidad de Ensenada.

7. También debemos mencionar que veinte años más tarde, la generación de los hijos renovó el tipo de narrativa y las imágenes utilizadas hasta entonces por madres, abuelas y organizaciones de derechos humanos. Los hijos adoptaron narrativas militantes, se interesaron por las infancias y en restituir las historias personales, recuperando la identidad política de los desaparecidos.

8. Entrevista a Melina Slobodián, 24 de abril de 2013, Ensenada.

9. Entrevista a Mario Díaz, 30 de agosto de 2015, Ensenada.

\section{Referencias bibliográficas}

Battiti, F. (2005). “Arte para deshabituar la memoria”. En Brodsky, Marcelo (2005). Memoria en construcción. El debate sobre la ESMA. Buenos Aires: La Marca editora.

Burucúa, J. E. y Kwiatkowski N. (2014). Cómo sucedieron estas cosas. Representar masacres $y$ genocidios. Buenos Aires, Argentina. Katz Editores.

Comisión Nacional sobre la Desaparición de Personas (CONADEP) [1984] (2016) Nunca Más. Informe de la Comisión Nacional sobre la Desaparición de Personas. Buenos Aires, Argentina. Ed. EUDEBA.

Crenzel, E. (2008). La historia política del Nunca Más: la memoria de las desapariciones en la Argentina. Buenos Aires, Argentina. Siglo XXI Editores.

Da Silva Catela, L. -2001- (2009). No habrá flores en la tumba del pasado. La experiencia de reconstrucción del mundo de los familiares de desaparecidos. La Plata: Al Margen.

Di María, G.; Sánchez Pórfido, E.; González, S. et al. (2009). Murales de la ciudad de La Plata, La Plata: Universidad Nacional de La Plata.

Feld, C., y Stites Mor, J. (comps.). (2009). El pasado que miramos, Memoria e imagen ante la historia reciente. Buenos Aires, Argentina. Ed. Paidós.

Feld, C. (2010). Imagen, memoria y desaparición. Una reflexión sobre los diversos soportes audiovisuales de la memoria. Aletheia Volumen 1 (1), octubre. Disponible en: http://www.aletheia.fahce.unlp.edu.ar/numeros/numero-1/pdfs/Feld-\%20Aletheia\%20 Vol\%201.N1.pdf

Freud, S. -1917- (1986). Duelo y Melancolía. Buenos Aires, Argentina. Ed. Amorrortu.

Friedlander, S. (2007). "Introducción” en Saúl Friedlander (Comp.) En torno a los límites de la representación. El nazismo y la solución final, Universidad Nacional de Quilmes.

Gatti, G. (2011). Identidades desaparecidas. Peleas por el sentido de los mundos de la desaparición forzada. Buenos Aires, Argentina. Ed. Prometeo Libros. 
García, S. y Belén, P. (2010). "Desapariciones en serie. Las marcas de lo invisible”. Actas de las XIII Jornadas Nacionales de Estética e Historia del Teatro Marplatense. Mar del Plata, Argentina. Ed. Fundación Destellos.

Halbwachs, M. -1968- (2011). La memoria colectiva. Buenos Aires: Miño y Dávila.

Halbwachs, M. -1925- (2004b). Los marcos sociales de la memoria, Barcelona, España. Ed. Anthropos.

Huyssen, A. (2002). En busca del futuro perdido. Cultura y memoria en tiempos de globalización. México. Ed. FCE.

Jelin, E. (2002). Los trabajos de la memoria. Madrid, España. Siglo XXI Editores.

Jelin, E. (2005). "Exclusión, memorias y luchas políticas", en: Mato, D. Cultura, política y sociedad Perspectivas latinoamericanas. Buenos Aires, Argentina. Consejo Latinoamericano de Ciencias Sociales.

LaCapra, D. (2005). Escribir la historia, escribir el trauma. Buenos Aires, Argentina. Ed. Nueva Visión.

LaCapra, D. (2006). Historia en tránsito. Experiencia, identidad, teoría crítica. Buenos Aires, Argentina. Ed. Fondo de Cultura Económica.

Laplanche, J. y Pontalis, J.B. (1971). Diccionario de psicoanálisis. Madrid, España. Ed Labor.

Longoni, A., Bruzzone, G. A. (2008). El Siluetazo. Buenos Aires, Argentina. Ed. Adriana Hidalgo.

Longoni, A. (2010). "Arte y Política. Políticas visuales del movimiento de derechos humanos desde la última dictadura: fotos, siluetas y escraches". Aletheia 1(1). Disponible en: http://www.aletheia.fahce.unlp.edu.ar/numeros/numero-1/ana-longoni.-arte-ypolitica.politicas-visuales-del-movimiento-de-derechos-humanos-desde-laultima-dictadurafotos-siluetas-y-escraches

Rancho Urutaú (2011). Un recorrido de nueves meses. Resumen de actividades del Espacio Cultural y de la Memoria El Rancho Urutaú. Ensenada.

Santner, E. (2007) "La historia más allá del principio del placer: algunas ideas sobre la representación del trauma”. En: Friedlander, S. En torno a los límites de la representación. Los nazis y la solución final. Quilmes, Argentina. Ed. Universidad Nacional de Quilmes.

Schindel, E. (2009). "Insertar el pasado en el presente: memoria y espacio urbano". En: Política y Cultura (31), México. Ed. Universidad Autónoma Metropolitana.

\begin{abstract}
The recent history of Argentinawas marked by the repression deployed during State terrorism of the seventies. This period has been considered as extreme and traumatic experience of high social and collective scope. This leads us to think about the particularities of the elaboration of recent past events of limit events by the affected societies. In this paperwe ask ourselves: In what ways can art collaborate in the elaboration of traumatic events? Based on a case study located in the city of Ensenada, province of Buenos Aires, we will analyze the procedures and scope of artistic practices that commemorate and pay homage to the disappeared and murdered people through a collective work of memories, in which family members and relatives of the victims actively participate.
\end{abstract}


Keywords: Traumatic events - Elaboration - Art - Memories - Ensenada.

Resumo: A história recente da Argentina foi marcada pela repressão desencadeada durante o terrorismo de Estado nos anos setenta. Este período tem sido considerado como experiência extrema e traumática de alto escopo social e coletivo. Isso nos leva a pensar sobre as particularidades da elaboração de eventos passados recentes de eventos limites pelas sociedades afetadas. Neste trabalho nos perguntamos: de que maneira a arte pode colaborar na elaboração de eventos traumáticos? A partir de um estudo de caso localizado na cidade de Ensenada, província de Buenos Aires, analisaremos os procedimentos e o escopo das práticas artísticas que comemoram e honram os desaparecidos e assassinados através de um trabalho coletivo de memórias, do qual participam ativamente, parentes e amigos íntimos das vítimas.

Palavras chave: Eventos traumáticos - Elaboração - Arte - Memórias - Ensenada.

[Las traducciones de los abstracts fueron supervisadas por el autor de cada artículo] 